\title{
PROPOSTA DE IMPLEMENTAÇÃO DO MARKETING DIGITAL PARA O ACRÉSCIMO DA CARTEIRA DE CLIENTES: ESTUDO DE CASO NA EMPRESA AGÊNCIA DE MOTOBOY EXPRESSO
}

\section{ARTIGO ORIGINAL}

MORAES, Gabriel Silva de ${ }^{1}$, CARVALHO, Emmily Cristina Vieira de ${ }^{2}$, JESUS, Franklin Pio de ${ }^{3}$, ALMEIDA, Victor da Silva ${ }^{4}$, SANTOS JÚNIOR, Aldemir Pereira dos $^{5}$, ROBERTO, José Carlos Alves 6

MORAES, Gabriel Silva de. Et al. Proposta de implementação do marketing digital para o acréscimo da carteira de clientes: estudo de caso na empresa Agência de Motoboy Expresso. Revista Científica Multidisciplinar Núcleo do Conhecimento. Ano. 06, Ed. 11, Vol. 02, pp. 127-149. Novembro 2021. ISSN: 24480959, Link de acesso:

https://www.nucleodoconhecimento.com.br/administracao/carteira-de-clientes, DOI: 10.32749/nucleodoconhecimento.com.br/administracao/carteira-de-clientes

\section{RESUMO}

A função do Marketing Digital permite uma comunicação interacional entre empresas e consumidores, auxiliando micro e pequenas empresas a conquistar mais benefícios de negócio. O presente artigo teve como objetivo realizar um estudo de caso na empresa AGM - Agência de Motoboy Expresso, do segmento de entregas. O artigo surgiu a partir da análise das áreas funcionais, onde a área de Marketing foi

\footnotetext{
${ }^{1}$ Graduanda do curso de Administração.

${ }^{2}$ Graduando do curso de Administração.

${ }^{3}$ Graduando do curso de Administração.

${ }^{4}$ Coorientador. Mestre em Engenharia de Processos. Pós-Graduando em Neuropsicopedagogia Institucional. Especialista em Gestão Estratégica de RH. Graduado em Administração e Pedagogia.

${ }^{5}$ Coorientador. Mestre em Ciências do Ambiente e Sustentabilidade na Amazônia. Especialista em Gestão dos Recursos Naturais e Meio Ambiente. Especialista em Metodologia do Ensino Superior. Graduado em Turismo e Administração.

${ }^{6}$ Orientador. Mestre em Engenharia de produção. Especialista Logística empresarial. Graduado em Administração com Ênfase em Marketing.
}

$\mathrm{RC}: 100636$

Disponível em: https://www.nucleodoconhecimento.com.br/administracao/carteirade-clientes 
identificada como a mais crítica. Este estudo pretende discutir: Como a implementação do marketing digital em micro e pequenas empresas prestadoras de serviços pode contribuir com o acréscimo da carteira de clientes? O objetivo geral do trabalho visa ampliar a carteira de clientes através da implementação do marketing digital na empresa AGM em 2021. A metodologia empregada consiste em um método quali-quantitativo, elaborando-se pesquisas bibliográficas e técnicas de coleta de dados. Neste artigo também foi utilizado a ferramenta de qualidade $5 \mathrm{~W} 2 \mathrm{H}$, para introdução de ações interventivas, como investir em campanhas de anúncios online com um gestor de tráfego, divulgar os serviços nas redes sociais de forma comercial e também homologar contratos com motoboys para trabalhos avulsos. Foi praticado um estudo de caso, por meio de entrevistas e questionários com o gestor, para que a partir desse ponto fosse fundamentado o corpus de análise. De acordo com pesquisas bibliográficas, o marketing digital em micro e pequenas empresas vem sendo cada vez mais implementado pelas organizações, e, dessa forma, adquirindo vários benefícios não só com o aumento da lucratividade, mas também criando uma relação de maior proximidade com o cliente. Com base no estudo, almeja-se que a empresa se destaque diante de seus concorrentes, aumentando a quantidade de clientes, com visibilidade de sua marca, conquistando parcerias e disponibilizando conteúdo relevante sobre seus serviços prestados.

Palavras-chave: Marketing digital, Redes sociais, Divulgação.

\section{INTRODUÇÃO}

Apresenta-se neste artigo um estudo realizado na empresa Agência de motoboy expresso, que atua na prestação de serviços de entregas em motocicletas. Ressaltase no trabalho, através de pesquisas realizadas em livro e artigos, a essência do marketing digital, além das suas ferramentas principais, e de como a sua implantação pode ser um benefício para a organização.

Verifica-se que não é feita a utilização do marketing digital na empresa. O marketing foi detectado, através do Diagnóstico Organizacional, como a área mais crítica. 
Aponta-se como objetivo geral do trabalho ampliar a carteira de clientes através da implementação do marketing digital na empresa AGM em 2021.

No trabalho científico a pergunta problema mostra o caminho no qual se deve seguir, pois ela mostra o que se deve investigar e responder de acordo com o tema. Segundo Carvalho et al. (2019, p.16), "um problema de pesquisa deve ter como suporte um questionamento, cujo valor científico será avaliado a partir do que se pretende observar ou descobrir por meio dele". Portanto: Como a implementação do marketing digital em micro e pequenas empresas prestadoras de serviços pode contribuir com o acréscimo da carteira de clientes?

Como introdução para a solução do problema, o trabalho apresenta a ferramenta de qualidade $5 \mathrm{~W} 2 \mathrm{H}$ para a implantação do marketing digital, fazendo com que a empresa ganhe repercussão na internet, crescendo assim sua carteira de clientes. Ressalta-se no trabalho o conceito de marketing digital, sua gestão, vantagem e estratégia. O procedimento metodológico levantado no trabalho consiste em um método quali-quantitativo, elaborando-se uma pesquisa descritiva e exploratória, tendo natureza básica, utilizando-se de pesquisas bibliográficas e técnicas de coleta de dados.

O conteúdo do artigo apresenta o esclarecer dos objetivos necessários para a implementação do marketing digital e de como pode ser iniciada por empresas de micro e pequeno porte.

Espera-se que a empresa tenha um reconhecimento de relevância na internet, podendo aumentar, além do número de clientes, a visibilidade da sua marca e possíveis parcerias com organizações maiores, além de disponibilizar mais informações referentes a detalhes sobre os tipos de serviços prestados pela mesma.

\section{FUNDAMENTAÇÃO TEÓRICA}

Compreende-se que o referencial bibliográfico é buscar e avaliar as melhores opiniões, teses e teorias disponíveis, desde que sejam relevantes para o estudo que

RC: 100636

Disponível em: https://www.nucleodoconhecimento.com.br/administracao/carteirade-clientes 
está sendo realizado. Alguns dos objetivos principais são misturar os principais modelos, aqueles que se mostrarem mais interessantes e plausíveis, e definir o conceito-chave. A colocação dessas teorias no referencial teórico demonstra que se realizou uma pesquisa a fundo do assunto, sendo elaboradas ideias aceitáveis do conteúdo escrito (LIMA e PEREIRA, 2018).

\subsection{CONCEITO DE MARKETING}

Marketing é um estudo do mercado, para melhor aproveitamento dele nas estratégias comerciais de uma empresa. É o conhecimento essencial para que uma organização defina quais mercadorias ou ofício podem atrair e manter um públicoalvo.

O marketing é a junção das tarefas sistemáticas de uma organização, a filosofia de um negócio, o desenvolvimento administrativo e social, além de auxiliar na elaboração de ideias, buscando sempre a troca com indivíduos, identificando quais as necessidades dos consumidores e buscando expandir (SILVA, 2015).

As empresas devem continuamente melhorar e inovar os seus planos de marketing, elaborando novos produtos e buscando sempre atingir as necessidades dos clientes, se atualizando e criando novos pontos fortes. Principalmente pelo crescimento da internet nos planos de marketing (KOTLER e KELLER, 2012).

\subsection{MARKETING DIGITAL}

O marketing digital é o conjunto de ações que uma organização ou empresa realiza no meio online, tendo o propósito de aumentar a sua carteira de clientes, desenvolver e crescer a sua marca, ou até abrir novos negócios.

A evolução da tecnologia aumentou e facilitou através de ferramentas os canais de informação e comunicação, ferramentas essas que são utilizadas diariamente pelas pessoas, tendo acesso rápido a redes sociais como Instagram e facebook, isso fez 
com que o marketing interativo se desenvolvesse e se torna-se conhecido hoje como marketing digital (BRITO, 2013).

O percorrer da evolução fez com que se tornasse mais fácil a utilização de dispositivos que permitissem 0 acesso à internet, o qual viabiliza novas oportunidades de negócios, além de poder ser usada para a comunicação de forma fácil, possibilitando a propagação de mercadorias ou serviços na internet para se vender e conseguir novos clientes. Essa ação é chamada de marketing digital (SARAIVA et al., 2017).

As publicidades são aplicadas no meio online, pois os consumidores têm como novo comportamento no dia a dia o manejar da internet, por isso o marketing digital tratase de um aglomerado de estratégias de marketing e publicidade. É significativo que as instituições usem o marketing digital sabendo das estratégias que a ferramenta disponibiliza (SOUSA et al., 2019).

\subsection{GESTÃO DE MARKETING DIGITAL}

O marketing digital possui a mesma gestão que normalmente as empresas possuem, que é a de organizar e controlar os recursos, visando cumprir o objetivo geral.

Cada área da empresa segue uma gestão voltada a seu melhor funcionamento, o marketing digital segue a gestão que coordena e planeja a equipe para adquirir recursos direcionados ao alcance dos resultados esperados pela empresa. Normalmente os objetivos seriam: majorar a produção feita pela equipe e elevar a eficácia das campanhas (MARTINS et al., 2021).

Ressaltam-se algumas vantagens no marketing digital: ter os custos baixos, pois há diferença entre o preço de anunciar na internet com o de anunciar na rádio ou televisão; o marketing um a um, pois é possível modificar os anúncios de formar rápida a fim de transmitir aquilo que o consumidor deseja e espera; a formação de banco de dados, por adquirir informações relevantes para se criar campanhas que 
agradem ao cliente, por meio de registros daquilo que o freguês mais espera ou procura em um produto, serviço ou empresa. (SILVA e ZUCHI, 2017).

\subsection{ESTRATÉGIA DE MARKETING DIGITAL}

Nos dias atuais, a presença do marketing digital é essencial, porém, definir as estratégias mais eficientes de marketing digital é imprescindível. É necessário ter um objetivo bem definido, ou seja, o esperado no final do marketing digital. Pode ser melhorar a indexação das páginas, aumentar o tráfego para um site, elevar as taxas de conversão, melhorar a relação com o freguês e até estabelecer a empresa no mercado digital.

Uma das primeiras estratégias de marketing digital para bons resultados online é a criação e o desenvolvimento de sites e blogs corporativos que consigam atrair clientes. Afinal, uma empresa precisa focar na elevação de um eficiente canal principal, que seja bem posicionado e transmita, sem nenhum ruído, os benefícios dos seus serviços

Para cada objetivo, é possível trabalhar estratégias específicas nas quais o cliente é sempre o foco principal. Dessa forma, o objetivo é conquistar a atenção das pessoas e construir uma união com elas através da produção de conteúdo - como blogspot, redes sociais, e-book, checklists etc.

As ferramentas mais usadas são o Google Ads, Facebook Ads, Instagram Ads e Linkedln Ads. Só essas duas primeiras plataformas são capazes de inserir seus possíveis anúncios nos 2 sites mais acessados como o Google e YouTube. Além de anunciar em 3 das 4 redes sociais mais utilizadas no mundo (SEBIN, 2016).

Quase que como um complemento ao site e as redes sociais estão os links patrocinados e as ações de mídia paga. Isso porque o investimento em plataformas de anúncios é uma das estratégias que geram retornos mais rápidos. Assim que as campanhas são ativadas, com a compra de palavras-chave ou de tráfego, elas já entram no ar e o público-alvo escolhido passa a ser impactado pelas campanhas.

RC: 100636

Disponível em: https://www.nucleodoconhecimento.com.br/administracao/carteirade-clientes 
Não só a agilidade superior às técnicas orgânicas de ganho de leads e clientes, mas também o controle sobre o orçamento, os filtros de segmentação e os relatórios de análise são outras vantagens dessas ferramentas (CROCCO et al., 2013).

No dia-a-dia são postadas inúmeras propagandas na internet, essa ação é realizada no meio online por decorrência da transição das pessoas para as redes e mídias sociais. Esse mecanismo de divulgação é uma estratégia do marketing digital que procura alcançar clientes no ambiente no qual se encontra o maior número de indivíduos (SOUSA et al., 2019).

\subsection{MARKETING NAS REDES SOCIAIS}

A estratégia que o marketing digital seguiu para cumprir seus objetivos, está focada na utilização das redes e mídias sociais para divulgação da marca da empresa. Procura criar formas de como entrar no cotidiano das pessoas, para que sua marca fique mais conhecida. Através das redes sociais que tem o custo baixo de divulgação, a marca se torna conhecida e atrativa para os consumidores, aumentando a sua carteira de clientes e melhorando através de feedbacks repassados (SARAIVA et al., 2017).

Dentro das redes sociais, as marcas adquirem personalidade através das publicações feitas pela empresa, demonstrando valores, atitudes e princípios, que se manifestam nos seus conteúdos. Assim sendo, elas acabam se tornando mais humanas e autênticas. A maioria das pessoas pensam que o marketing nas redes sociais se restringe a transmitir em posts e em feeds de notícias, porém existem muitas estratégias e objetivos envolvidos.

Para ter um resultado favorável é preciso seguir essas atividades, visto que através das redes sociais é possível exibir os bastidores da empresa, apresentar as pessoas que cuidam da marca, além de ter um meio de comunicação fácil com os clientes e de passar informações relevantes. É necessário avaliar quais são as redes sociais 
mais apropriadas para o negócio, os objetivos gerais e específicos de marketing, a capacidade de uma equipe e o perfil do público (KOTLER, 2017).

Nos dias de hoje, as redes sociais provocam um grande impacto no relacionamento de empresas e clientes, e tornaram-se uma parte essencial no Marketing Digital. Entretanto, não pode substituir e eliminar a execução de um site para as organizações. Nesse contexto, para aquelas de pequeno porte, as Fan Pages são mais indicadas em Redes Sociais, preferencialmente naquelas que possuem maior número de acessos. As mesmas devem começar com conteúdo que façam uma breve apresentação daquilo que a empresa oferece e independente de seu tamanho, precisam unir essas duas ferramentas. Mesmo que as Redes sociais delimitam o volume de suas publicações, também proporcionam oportunidade de postagens mais curtas, que levará uma pessoa a entrar nos Websites, que estará "linkado" aos seus posts, a fim de que a mesma seja redirecionada ao site oficial da empresa, onde terá uma informação mais completa (GOMES e REIS, 2015).

Dessa maneira, ambas as partes caminham de mãos dadas, já que a conexão nesse meio virtual aproxima e agiliza na troca de informações e nas compras de produtos ou serviços.

\subsection{CONCEITO DE E-MAIL MARKETING}

O e-mail marketing é uma ferramenta de marketing direto e de baixo custo, pois a comunicação é direta com o freguês ou potencial cliente. O conteúdo é feito com o propósito de apresentar seus negócios, entreter e informar.

O e-mail foi um dos primeiros meios de comunicação, logo no surgimento da internet. Entretanto, o mau uso desta ferramenta, fez com que muitas empresas vissem como algo negativo, o uso em excesso. Porém, atualmente, o mercado amadureceu e o e-mail voltou a ser muito utilizado (BRUM, 2019).

No entanto, é necessário segmentar o seu público-alvo e saber como utilizar essa ferramenta. A empresa precisa pedir permissão e o cliente precisa sentir que pode

RC: 100636

Disponível em: https://www.nucleodoconhecimento.com.br/administracao/carteirade-clientes 
"aceitar" ou "ignorar" em manter relação com a empresa, diante dessa dinâmica, a empresa terá mais confiança e integridade, desenvolvendo um relacionamento horizontal de empresa x cliente (KOTLER, 2017).

Além disso, o utilizar do e-mail marketing é prático, ágil e barato. Pode ser aplicado em: E-mail de rotina, como informativos; E-mail de suporte ao cliente, também muito importante, pois é o meio personalizado para se comunicar com o cliente; e Newsletter que pode ser enviado semanalmente com o objetivo de promover a ligação da empresa com o cliente (FELIPINI, 2014).

Para pequenas empresas, o desafio do uso do e-mail marketing é fazer com que o conteúdo seja muito útil, e para isso, é significativo que a empresa envie para as pessoas certas, que realmente irão ler esses e-mails. A compra de listas de e-mails, não é uma opção eficaz, além de que, quase sempre, o público não procura pelo serviço que está sendo divulgado.

\subsection{CONCEITO DE MARKETING DE CONTEÚDO}

A construção do conteúdo procura através de objetivos atingir um público-alvo para conhecer melhor seus negócios oferecidos, através de um conteúdo de qualidade e relevante.

O marketing de conteúdo é uma sequência de ações que tem o objetivo de formar e divulgar um conteúdo valioso. Trata-se de envolver pessoas por meio do compartilhamento de informações com o objetivo de atrair e convencer os clientes de que precisam solucionar seu problema com sua mercadoria ou serviço (PULLIZZI, 2016).

Apresentar um conteúdo de relevância e conhecer bem seu público alvo é a origem para uma divulgação eficiente. As pessoas estão sempre à procura de conteúdo, mesmo enquanto estão assistindo tv, podem usar o celular ao mesmo tempo, e fazer buscas de algo novo que aparece em comerciais (ANTUNES, 2017). 
O marketing de conteúdo torna as empresas menos suscetíveis às influências sazonais, visto que, se um conteúdo é feito com alta qualidade, sempre será relevante, independente do tempo, será disponível e acessível. O conteúdo utiliza mensagens para educar o cliente, a fim de encontrar e conhecer uma solução, serviço, produto (REZ, 2016).

Deste modo, o marketing de conteúdo é tudo aquilo que envolve os consumidores finais de uma mercadoria ou serviço, o qual pode ser consumido em sites, e-mails, eventos presenciais, vídeos, mídias sociais. Para um bom conteúdo, alguns pontos precisam ser levados em consideração, como por exemplo: ter credibilidade, ser compartilhável, interessante, diferente e relevante.

Além disso, o uso desta ferramenta pode trazer benefícios como, novos clientes, aumentar a visibilidade, agregar valor à sua mercadoria ou serviço e ganhar confiança para que os clientes permaneçam na empresa.

\section{MATERIAIS E MÉTODOS}

O método é um dos pontos principais e mais importantes da pesquisa científica, pois ele indica com clareza o caminho que deve ser seguido. Além disso, existem também métodos mais amplos como: método indutivo e método dedutivo, entre outros que variam de acordo com cada pesquisa (CHOTOLLI et al., 2018).

Assim sendo, recorreu-se a métodos que mais se adequam no obter de informações, com a necessidade de apresentar uma solução de eficiência para o problema.

\subsection{PROCEDIMENTOS METODOLÓGICOS}

O método qualitativo é a interpretação do pesquisador sobre as informações e dados coletados através de entrevistas que podem ser preferencialmente descritivas e analisadas por um processo indutivo. Enquanto, o método quantitativo é utilizado por 
meio de dados numéricos baseados em dados matemáticos, como por exemplo, probabilidades, porcentagens e estatísticas (PARREIRA et al., 2018).

Com isso, levantou-se um método misto quali-quantitativo, para analisar os dados utilizando-se na primeira etapa, uma análise qualitativa de pesquisa exploratória com a aplicação de questionários e entrevista. Na segunda etapa, usou-se uma análise quantitativa com os resultados obtidos na primeira etapa, criando, assim, gráficos.

\subsubsection{QUANTO À NATUREZA}

A pesquisa aplicada tende a proporcionar conhecimento para a aplicação prática e dirigida à solução de problemas. A pesquisa básica tem a finalidade de aprofundar o conhecimento científico sobre um estipulado tema, a qual se divide em básica pura e básica estratégica (CAMÕES et al., 2014).

Contudo, adotou-se, neste artigo, a pesquisa de natureza básica estratégica, pois tem o intuito de se aprofundar no assunto com uma proposta de solução para o problema.

\subsubsection{QUANTO AOS FINS}

A investigação exploratória é produzida em campo com a coleta de dados, isso acontece quando não há registro escrito em livros, artigos e trabalhos acadêmicos. $\mathrm{A}$ investigação descritiva, é a base que serve como conhecimento para determinado fenômeno, mas não possui o comprometimento para explicá-lo (VERGARA, 2016).

Diante disso, elaborou-se uma pesquisa descritiva e exploratória através de materiais e métodos para implementar o marketing digital em micro e pequenas empresas prestadoras de serviços, a fim de contribuir com o acréscimo da carteira de clientes. 


\subsubsection{QUANTO AOS MEIOS}

O cuidado na aplicação das técnicas de coleta de dados é fundamental para evitar erros que possam ser recorrentes, seja por informantes tendenciosos ou inexperiência do entrevistador. Algumas técnicas utilizadas são: Formulários, questionários, entrevistas, observação, coleta documental, testes, técnicas mercadológicas e medidas de opinião e de atitudes (LAKATOS e MARCONI, 2017).

Realizou-se pesquisas bibliográficas no decorrer da produção do conteúdo, além de técnicas de coleta de dados, como entrevistas, questionários e observações, procurando, em detalhes, dados efetivos.

\subsection{CARACTERIZAÇÃO DA EMPRESA}

Fundada em 23 de setembro de 2008 por Charlie Nonato Simões, no Bairro Parque dez de novembro, na cidade de Manaus do estado do Amazonas, a Agência de Motoboy Expresso (AGM) funcionou, de início, somente com o próprio fundador e mais dois amigos. A empresa é de pequeno porte e atua nos segmentos de entregas em motocicletas nos variados ramos.

Hoje, a AGM é uma empresa com cerca de 13 colaboradores diretos em seu quadro de pessoal e vem sendo gradualmente reconhecida. $O$ endereço do escritório da empresa se localiza atualmente na Rua Samuel Pereira de Lima, 38, 69036-766, Manaus/AM.

\section{RESULTADOS E DISCUSSÕES}

Compreende-se através da pesquisa realizada, no diagnóstico organizacional, o desempenho de cada área da empresa Agência de motoboy expresso. No gráfico 1, apresenta-se os resultados da melhor para a pior área funcional, observado através da coleta de dados. 
Gráfico 1: Medição de desempenho por área funcional

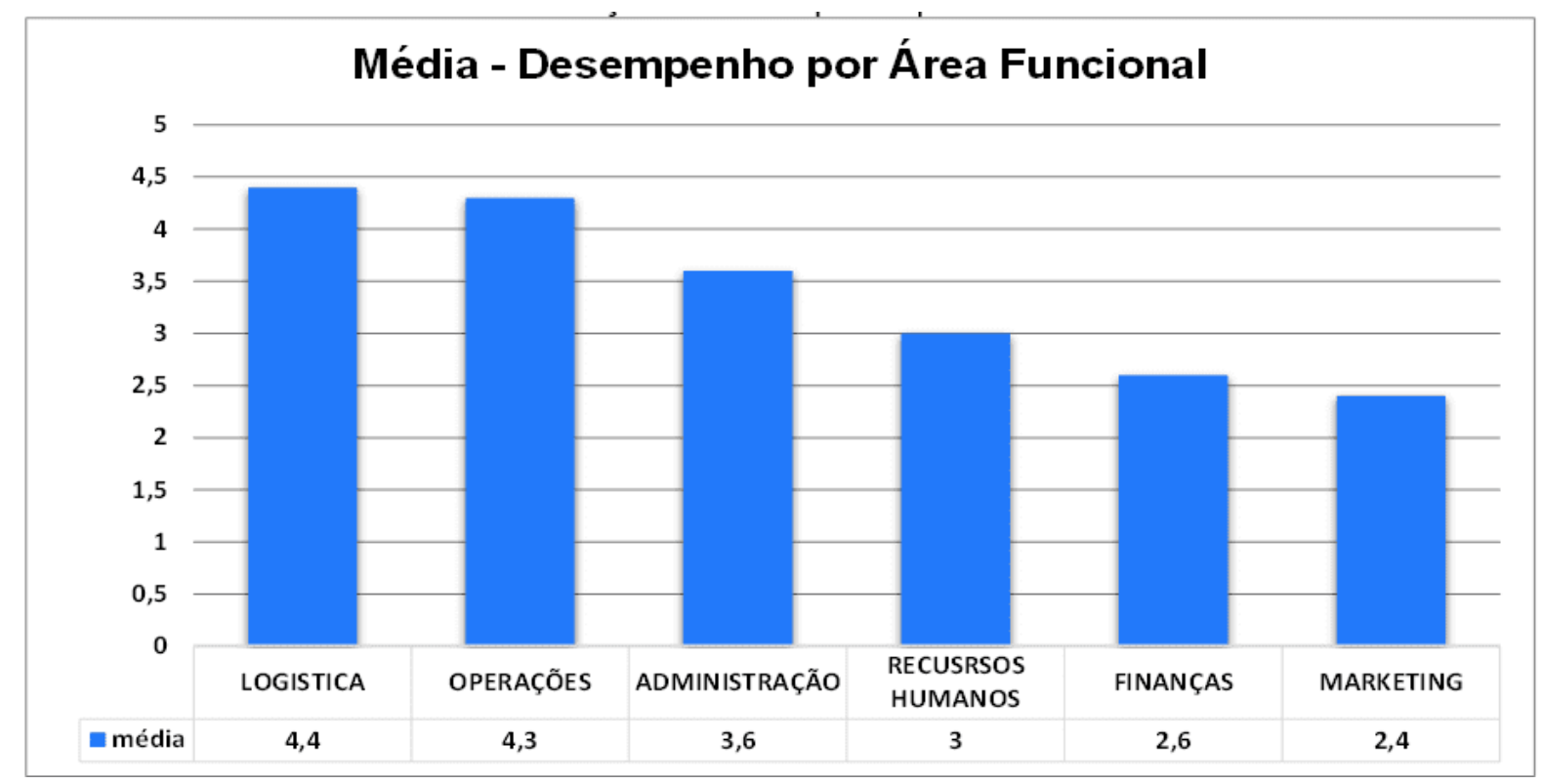

Fonte: Autores (2021).

Identifica-se que a empresa tem a área de logística e operações como as de melhor desempenho; administração, recursos humanos e finanças obtiveram desempenho mediano. Já a área de marketing apresentou um desempenho baixo, sendo considerada a área crítica da empresa. Esse resultado se dá a partir da coleta de dados feita através da utilização de questionários e da observação dos autores durante o processo do diagnóstico organizacional.

RC: 100636

Disponível em: https://www.nucleodoconhecimento.com.br/administracao/carteirade-clientes 
Quadro 01: Marketing.

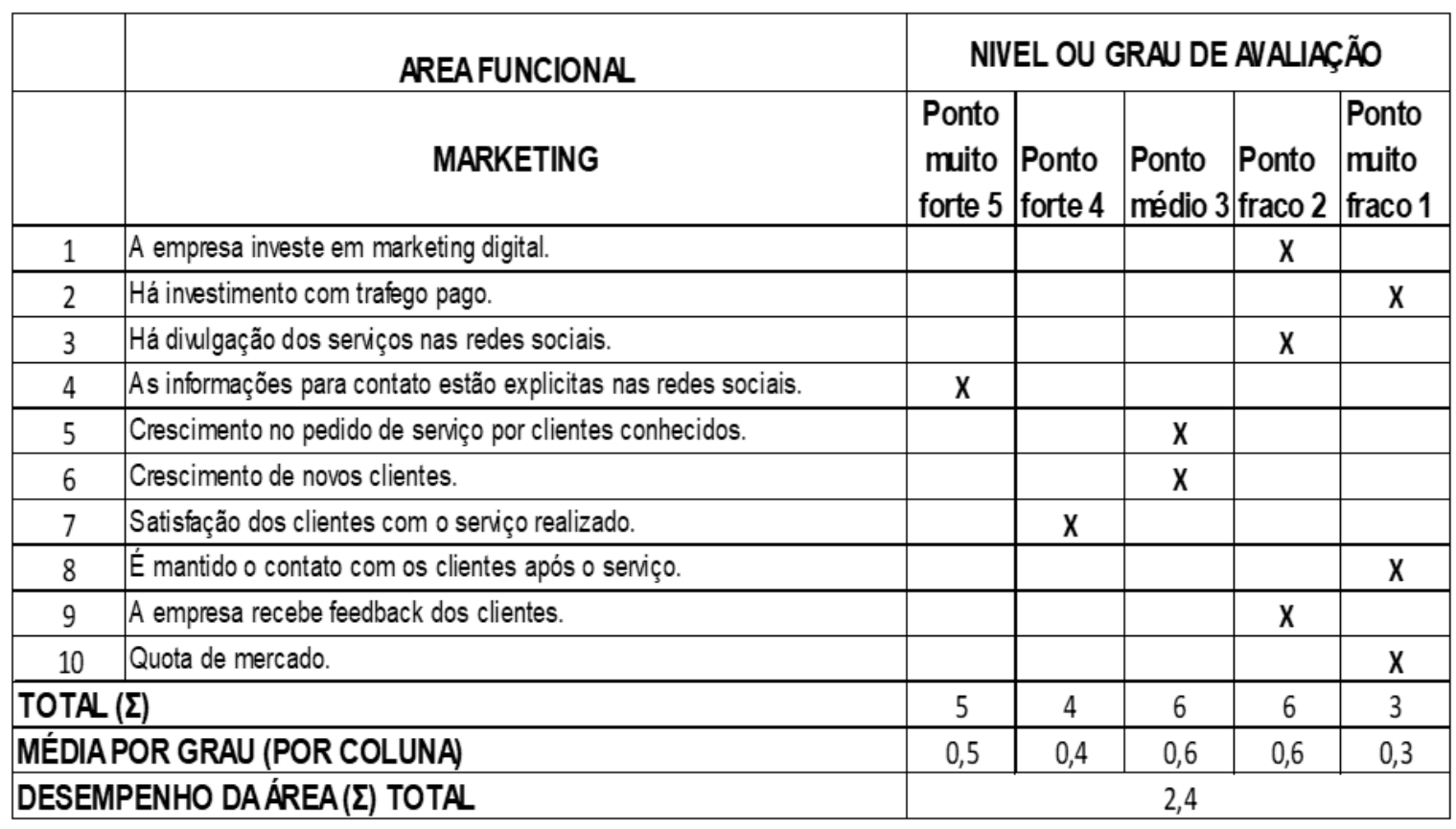

Fonte: Autores (2021).

Foi constatado através dos indicadores de desempenho que o marketing é a pior área da empresa AGM. O investimento em marketing digital, divulgação em redes sociais, sites e contato com os clientes para se ter um feedback não é realizado ou não é executado da maneira correta. É significativo a utilização do marketing digital para a divulgação dos serviços e produtos de uma instituição no contexto do mercado atual. Além disso, a empresa não homologa contratos com motoboys, deixando uma carga de trabalho grande para seus funcionários e não possui equipamentos como baús bauleto de reserva. Portanto, o problema da pesquisa consiste em: como a implementação do marketing digital em micro e pequenas empresas prestadoras de serviços pode contribuir com o acréscimo da carteira de clientes? 


\subsection{PLANEJAMENTO DAS AÇÕES}

O planejamento de ações compõe-se de objetivos e metas organizadas através de uma metodologia que visa cumprir as etapas no prazo, melhorando ou corrigindo um problema gerado na empresa. Contém a ação, cronologia, duração e o custo de cada ação interventiva.

Quadro 02: Ações interventivas

\begin{tabular}{|c|c|c|c|c|}
\hline Item & Ações Interventivas & Cronologia & Duração & Custo \\
\hline 1 & $\begin{array}{c}\text { nvestir em campanhas de anuncios } \\
\text { online com um gestor de tráfego }\end{array}$ & Setembro/2021 & ação continua & $\mathrm{R} \$ 500,00 /$ Mensal \\
\hline 2 & $\begin{array}{c}\text { Divulgar os serviços nas redes } \\
\text { sociais de forma comercial }\end{array}$ & Setembro/2021 & ação continua & $\mathrm{R} \$ 200,00 /$ Mensal \\
\hline 3 & Implementar o E-mail marketing & Outubro/2021 & ação continua & $\mathrm{R} \$ 190,00 /$ Mensal \\
\hline 4 & $\begin{array}{c}\text { Homologar contratos com } \\
\text { motoboys para trabalhos avulsos }\end{array}$ & Novembro/2021 & 15 Dias & $\mathrm{R} \$ 200,00$ \\
\hline 5 & $\begin{array}{c}\text { Adquirir como reserva cinco baús } \\
\text { bauleto personalizados com o } \\
\text { emblema da empresa }\end{array}$ & Novembro/2021 & 10 Dias & $\mathrm{R} \$ 1.650,00$ \\
\hline Valor Total| & & & $\mathrm{R} \$ 2.740,00$ \\
\hline
\end{tabular}

Fonte: Autores (2021).

O quadro acima apresenta a proposta de solução de cada etapa que foi desenvolvida através da ferramenta de gestão da qualidade $5 \mathrm{~W} 2 \mathrm{H}$, é uma ferramenta que se utiliza com o propósito de identificar as ações e responsabilidades de execução, com o objetivo de responder 7 perguntas fundamentais. Cada ação tem o seu tempo de implantação, alguns com duração contínua tendo custo mensal e outras com a implantação que leva dias. Cada uma deve seguir o seu tempo cronológico, para que a empresa tenha condições de aplicá-las da melhor forma possível. 
Espera-se através dessas ações interventivas que a empresa corrija a falta da utilização das ferramentas básicas do marketing digital, além de ampliar de forma profissional a contratação de seus funcionários e de se prevenir com a possível falta de baús bauleto que servem para proteger a mercadoria transportada.

\subsubsection{INVESTIR EM CAMPANHAS DE ANÚNCIOS ONLINE COM UM GESTOR DE TRÁFEGO}

De acordo com os dados coletados, verificou-se que a empresa não fazia investimentos em tráfego pago, e compreendia pouco do assunto. No quadro 3 apresenta-se o planejamento para a implantação do processo na empresa Agência de Motoboy Expresso.

Quadro 03: Investir em campanhas de anúncios online com um gestor de tráfego.

\begin{tabular}{|c|c|}
\hline & $\begin{array}{c}\text { Investir em campanhas de anuncios online com um gestor de } \\
\text { tráfego }\end{array}$ \\
\hline O que? & $\begin{array}{c}\text { Investir em campanhas de anuncios online com um gestor de } \\
\text { tráfego ampliando a divulgação }\end{array}$ \\
\hline Por quê? & $\begin{array}{c}\text { Para ampliação dos clientes em vários segmentos e se tornar } \\
\text { referência }\end{array}$ \\
\hline Onde? & Agência de motoboy expresso \\
\hline Quando? & Terceira semana de setembro 2021 \\
\hline Quem? & Um Gestor de Tráfego \\
\hline Como? & $\begin{array}{c}\text { Investindo na criação e divulgação das campanhas de anuncios no } \\
\text { meio onlines }\end{array}$ \\
\hline Quanto? & $\mathrm{R} \$ 500,00 /$ mensal \\
\hline
\end{tabular}

Fonte: Autores (2021).

O quadro acima apresenta a implantação do investimento em tráfego pago, tendo em vista que a empresa não possui conhecimento para fazer o mesmo, desta forma, foi necessário contratar um profissional da área conhecido como gestor de tráfego, no qual utiliza de ferramentas do Google ou Facebook para criar campanhas e divulgá-las na internet.

RC: 100636

Disponível em: https://www.nucleodoconhecimento.com.br/administracao/carteirade-clientes 
Espera-se que através deste investimento mais clientes possam conhecer o serviço da empresa independente da área de Manaus, pois a divulgação online pode se espalhar facilmente por toda cidade.

\subsubsection{DIVULGAR OS SERVIÇOS NAS REDES SOCIAIS DE FORMA COMERCIAL}

Em época de informação digital, a publicação em redes sociais tornou-se uma necessidade para empresas que almejam ser notadas pelo público-alvo, independentemente de qual seja seu segmento. Entende-se que a estratégia de marketing digital que utiliza as principais redes sociais como ferramentas de promoção de uma marca, obedece a uma dinâmica própria, mais sutil e estruturada do que a verificada em outras estratégias de marketing.

Quadro 04: Divulgar os serviços nas redes sociais de forma comercial.

\begin{tabular}{|c|c|}
\hline & Divulgar os serviços nas redes sociais de forma comercial \\
\hline O que? & Divulgar os serviços nas redes sociais de forma comercial \\
\hline Por quê? & $\begin{array}{c}\text { Para aumentar a capacidade da marca de se relacionar com o } \\
\text { público alvo de forma mais segmentada }\end{array}$ \\
\hline Onde? & Agência de motoboy expresso \\
\hline Quando? & Quarta semana de setembro 2021 \\
\hline Quem? & Um especialista em marketing digital \\
\hline Como? & Atráves de estratégias para divulgação nas redes sociais \\
\hline Quanto? & R $\$ 200,00 /$ mensal \\
\hline
\end{tabular}

Fonte: Autores (2021).

O quadro acima retrata uma campanha estratégica. Seguindo essas ferramentas da maneira correta, é possível obter dados comportamentais e demográficos que podem ser utilizados como base para filtrar o público com o qual se deseja trabalhar, visto que o consumidor tem passado por mudanças comportamentais nas últimas décadas e, para acompanhar suas necessidades, é preciso utilizar estratégias inovadoras. 
Espera-se que com tal meta, os serviços da AGM se aproximem mais do públicoalvo e conheça seus desejos e carências com mais precisão, algo que permitirá com que a equipe de colaboradores obtenha resultados importantes sobre a parcela do mercado que deseja impactar, alinhando assim, um bom planejamento a uma visão clara de que as redes sociais são suas aliadas e que podem fazer a diferença na captação de novos clientes.

\subsubsection{IMPLEMENTAR O E-MAIL MARKETING:}

Tem como objetivo criar e manter o relacionamento com clientes, possibilitando mais resultados nas vendas e serviços e melhorando a retenção. É a estratégia de envio de e-mails para uma determinada lista de contatos para estabelecer uma comunicação com um destinatário e cumprir certos propósitos de marketing, feito através de ferramentas de automação e utilização do e-mail em campanhas de marketing digital.

Quadro 05: Implementar o E-mail marketing.

\begin{tabular}{|c|c|}
\hline & Implementar o E-mail marketing \\
\hline O que? & Implementar o E-mail marketing \\
\hline Por quê? & A fim de aumentar e fidelizar as vendas de serviços para o mesmo \\
cliente
\end{tabular}

Fonte: Autores (2021).

O plano no quadro expõe a preocupação da organização em implementar a peça de e-mail marketing como solução para um problema identificado. Funcionado através de uma tomada de decisão sobre o que os clientes estão gostando ou não na Agência de Motoboy Expresso - AGM. Apresenta um conjunto de providências para

RC: 100636

Disponível em: https://www.nucleodoconhecimento.com.br/administracao/carteirade-clientes 
que os serviços oferecidos sejam aprimorados, bem como respostas sejam obtidas frente aos desafios que se apresentam durante o mesmo.

Almeja-se que, por meio de fácil acesso, esta ação corresponda a toda necessidade do cliente através de e-mail, tornando-se uma maneira de alcançar diretamente maior número de clientes potenciais por meio de um contato direto com os colaboradores da AGM. Tudo isso na tela de um dispositivo, podendo estar adaptada perfeitamente a um Smartphone, tablet ou notebook, com um custo relativamente baixo em comparação com outros tipos de publicidade ou anúncios patrocinados.

\subsubsection{HOMOLOGAR CONTRATOS COM MOTOBOYS PARA TRABALHOS AVULSOS}

A contratação por meio de contratos com pessoas que possuam CNPJ como MEl, está cada vez mais comum entre as empresas, visto que, reduz bastante os custos com obrigações trabalhistas como: horas extras, adicional noturno, férias, contribuição previdenciária, exames admissionais e demissionais.

Quadro 06: Homologar contratos com motoboys para trabalhos avulsos.

\begin{tabular}{|c|c|}
\hline O que? & Homologar contratos com motoboys para trabalhos avulsos \\
\hline Por quê? & $\begin{array}{c}\text { Reduzir custos com salários mensais, férias, exames admissionais e } \\
\text { demissionais e flexibilizar acordo por horas e serviços prestados }\end{array}$ \\
\hline Onde? & Agência de motoboy expresso \\
\hline Quando? & Primeira semana de novembro 2021 \\
\hline Quem? & Empresa e motoboy \\
\hline Como? & $\begin{array}{c}\text { Contrato acordado por horas e serviços prestados com motoboy que } \\
\text { possua CNPJ aberto como MEl }\end{array}$ \\
\hline Quanto? & $\mathrm{R} \$ 200,00$ \\
\hline
\end{tabular}

Fonte: Autores (2021). 
No quadro acima, foi proposto que a empresa adotasse esse meio de contratação para diminuir a burocracia. Com este meio, é benéfico para ambas as partes, o motoboy poderá emitir uma nota fiscal para empresa AGM, e pode ganhar até mais do que um contrato CLT, que possui vários descontos. E com isso, verificou-se que a empresa terá muito mais flexibilidade e diminuição de custos.

Deseja-se através desse meio de contratação que os clientes não precisem esperar muito tempo para ter seu pedido entregue, mesmo em um dia de grande movimentação de atendimentos.

\subsubsection{ADQUIRIR COMO RESERVA CINCO BAÚS BAULETO PERSONALIZADOS COM O EMBLEMA DA EMPRESA}

A fim de melhorar a divulgação da empresa, observou-se um investimento na compra de cinco baús bauleto personalizados, o que trará mais visibilidade de seus contatos. Este meio de comunicação é bastante eficiente, pois permitirá que qualquer pessoa conheça seus serviços. Além disso, permanecer com uma reserva de baús bauleto previne que nem uma motocicleta fique sem a proteção para transportar a mercadoria.

Quadro 07: Adquirir como reserva cinco baús bauleto personalizados com 0 emblema da empresa.

\begin{tabular}{|c|c|}
\hline & $\begin{array}{l}\text { Adquirir como reserva cinco baús bauleto personalizados } \\
\text { com o emblema da empresa }\end{array}$ \\
\hline O que? & $\begin{array}{l}\text { Adquirir como reserva cinco baús bauleto personalizados com o } \\
\text { emblema da empresa }\end{array}$ \\
\hline Por quê? & Para melhorar a ampliação da empresa e ampliar atendimento \\
\hline Onde? & Agência de motoboy expresso \\
\hline Quando? & Terceira semana de novembro 2021 \\
\hline Quem? & Responsável pelo setor de compras \\
\hline Como? & Por meio de cotações em lojas especializadas em motos \\
\hline Quanto? & $\mathrm{R} \$ 1.650,00$ \\
\hline
\end{tabular}

Fonte: Autores (2021).

RC: 100636

Disponível em: https://www.nucleodoconhecimento.com.br/administracao/carteira$\underline{\text { de-clientes }}$ 
Os baús bauleto auxiliam bastante no transporte de cargas, e existem vários modelos e tamanhos medidos em litros, dependendo de cada necessidade. Para a empresa AGM, sugeriu-se um baús bauleto acima de 80 litros, para ter um tamanho ideal compatível com a personalização.

Espera-se que, com baús bauleto reserva, possa-se sempre haver um meio de transportar a carga com a máxima segurança possível caso venha acontecer de um dos baús bauleto quebrar ou de se contratar um novo entregador.

\section{CONSIDERAÇÕES FINAIS}

Esta pesquisa teve como finalidade avaliar o ambiente organizacional em que a empresa está introduzida. Através de entrevistas e pesquisas, foram identificados os fatores internos e externos da empresa que interferem nas atividades institucionais e os pontos que envolvem a gestão administrativa de uma organização. Abordou-se 0 relacionamento empresa e cliente e monitorou-se as suas compreensões com o intuito de que essa análise permita que futuras pesquisas desenvolvam estratégias mais interessantes a fim de formar uma vasta carteira de clientes ativos na empresa.

Proveu-se também, no que se refere a satisfação de clientes, uma maior estabilidade em conhecer, fidelizar e identificar sua carteira, além de destacar a importância dos principais responsáveis pela administração em mídias sociais da empresa em direcionar esforços para a promoção das interações dos usuários da rede, uma vez que essas interações possuem conexões com a marca no mundo virtual. Isso a fim de destacar a importância da relação com os clientes em meios virtuais por meio das redes sociais.

O perfil da empresa foi devidamente analisado gerando maior compreensão sobre o serviço, porte e principais tecnologias usadas pela organização. Isso possibilitou o conhecimento das características do quadro funcional da Agência de Motoboy Expresso que, em sua maioria é composta por homens, com poucos gestores, baixo nível de funcionários com nível superior e quantidade de mão de obra disponível. Tal 
análise permitiu identificar se a empresa possui ou não os requisitos básicos para o desenvolvimento de seu negócio.

As áreas funcionais da Empresa Estudada foram: Logística, operações, administração, recursos humanos, finanças e marketing. Logística e operações obtiveram o melhor desempenho, sendo pontos fortes. Administração, finanças e recursos humanos, obtiveram desempenho mediano. O Marketing, por sua vez, foi considerado a área de pior avaliação. Enquanto a sua análise externa apresentou fatores que demandam muita atenção, pois seus concorrentes crescem e tomam espaço de mercado rapidamente inovando nas formas de divulgação e melhorando sua imagem perante a população, a AGM evolui de forma lenta não se atentando ao ambiente externo na qual se encontra.

Como a implementação do marketing digital em micro e pequenas empresas prestadoras de serviços pode contribuir com o acréscimo da carteira de clientes? Em resposta a questão problemática deste trabalho, obteve-se também, no que se refere a satisfação de clientes, uma maior estabilidade em conhecer, fidelizar e identificar sua carteira, além de destacar a importância dos principais responsáveis pela administração em mídias sociais da empresa em direcionar esforços para a promoção das interações dos usuários da rede, uma vez que essas interações possuem conexões com a marca no mundo virtual. Isso para que se destaque a importância da relação com os clientes em meios virtuais por meio das redes sociais.

Através de uma análise interna e externa, foi possível identificar com mais detalhes seus pontos fortes e fracos e a melhor no meio empresarial. A mesma ainda precisa reajustar muitos dos seus aspectos, mas em geral possui grandes pontos positivos de relevância para o mercado. Ademais, apesar das forças internas, a empresa está muito vulnerável às oscilações dos preços no mercado que podem resultar num aumento do custo, do preço praticado ou perda de rentabilidade. Tal ligação de cooperação e proximidade que vem buscando a desenvolver com os seus fregueses e o seu espírito de inovação tem concedido aperfeiçoamento de serviços e aproximação ainda mais das necessidades dos clientes. 
Diante do exposto, conforme o diagnóstico, descobriu-se que seu problema gira em torno das divulgações que não têm a atenção e o investimento adequado. A falta de interesse no marketing digital, deixou a empresa atrás de suas rivais, tendo em conta que no cenário atual grande parte da população adquire informação e entretenimento através do meio digital. Neste sentido, esta pesquisa promoveu uma visão geral de uma organização, mostrando com essas variações, o resultado dos indicadores de interação, obtendo-se uma correlação positiva com o crescimento da marca da empresa, e abrindo assim, estudos para novas soluções empresariais.

\section{REFERÊNCIAS}

ANTUNES, J. L. Marketing de Conteúdo: estratégias para entregar o que o público quer consumir. São Paulo: Casa do Código, 2017.

BRUM, J. Marketing Digital. 1르 ed. São Paulo; Tecnocorp, 2019.

BRITO, A. L. S. Fundamentos de marketing. Aracaju: UNIT, 2013.

CARVALHO, L. O. R. et al. Metodologia Científica: Teoria e Aplicação na Educação a Distância. Petrolina: Universidade Federal do Vale do São Francisco, 2019, 16 p.

CAMÕES, M. R. de S. et al. A Importância da Pesquisa Aplicada: desafios e experiências na ENAP. Brasília DF: ENAP, 2014.

CHOTOLLI, W. P. A concepção geral da pesquisa. In: Thiago Mazucato (org.), Metodologia da Pesquisa e do Trabalho Científico. Penápolis - SP: FUNEPE, 2018.

CROCCO, L.; et al. Decisões de Marketing os 4 Ps. v. 2. São Paulo: editora Saraiva, 2013.

FELIPINI, D. E-mail Marketing Eficaz: Como conquistar e fidelizar clientes com uma newsletter. São Paulo: Blue Editora e Livraria LTDA, 2014.

RC: 100636

Disponível em: https://www.nucleodoconhecimento.com.br/administracao/carteirade-clientes 
GOMES, C. F.; REIS, H. M. Marketing digital: sites $\mathbf{x}$ redes sociais no Brasil. Revista Interface Tecnológica da FATEC Taquaritinga. p. 53-62, 2015. Disponível em: <www.fatectq.edu.br/Interfacetecnologica>. Acesso em: 07 de Setembro de 2021.

KOTLER, P. et al. Marketing 4.0: Do tradicional ao digital. Rio de Janeiro: GMT Editores Ltda, 2017.

KOTLER, P. KELLER, K. L. Administração de Marketing. 14ª edição. São Paulo: PEARSON, 2012.

LAKATOS, E. M.; MARCONI, M. de A. Fundamentos de Metodologia Científica. $8^{a}$ ed. São Paulo: Atlas S.A, 2017.

LIMA, P. G.; PEREIRA, M. C. (orgs). Pesquisa científica em ciências humanas: uma introdução aos fundamentos e eixos procedimentais. Uberlândia: Editora Navegando Publicações, 2018.

MARTINS, R. N. S. et al. Propor Melhorias No Setor De Marketing: Estudo De Caso Na Empresa Tucuxi Radio Taxi. Revista Científica Multidisciplinar Núcleo do Conhecimento. Ano 06, Ed. 05, Vol. 16, pp. 156-175. Maio de 2021. ISSN: 24480959,

https://www.nucleodoconhecimento.com.br/administracao/setor-de-marketing, DOI: 10.32749/nucleodoconhecimento.com.br/administracao/setor-de-marketing.

PARREIRA, F. J. et al. Metodologia da Pesquisa Científica. Santa Maria - RS: UAB/NTE/ UFSM, 2018.

PULLIZZI, J. Como contar uma história diferente, destacar-se na multidão e conquistar mais clientes com menos marketing. São Paulo: DVS Editora, 2016.

REZ, R. Marketing de Conteúdo: a moeda do século XXI. São Paulo: DVS Editora, 2016. 
SARAIVA, P. M. et al. Marketing com digital. Porto Alegre: Simplíssimo, 2017.

SEBIN, P. A. Marketing Digital para Empreendedores. São Paulo: Endeavor Brasil, 2016.

SILVA, G. F.; ZUCHI, J. D. Impacto da Tecnologia da Informação sobre o Marketing. Revista Interface Tecnológica, [S.I.], v. 14, n. 1, p. 12, jul. 2017. Disponível em: <http://159.203.166.88/index.php/interfaceztecnologica/article/view/143>. Acesso em: 06 de Setembro de 2021.

SILVA, L. A. Administração de Marketing. Rio de Janeiro: Copyright SESES, 2015.

SOUSA, D. A. et al. Estratégias de marketing digital nas mídias sociais como ferramentas de aproximação entre cliente e empresa. Revista Científica Multidisciplinar Núcleo do Conhecimento. Ano 04, Ed. 11, Vol. 03, pp. 128-145. Novembro de 2019. ISSN: 2448-0959. Disponível em: https://www.nucleodoconhecimento.com.br/marketing/marketing-digital. DOI: 10.32749/nucleodoconhecimento.com.br/marketing/marketing-digital.

VERGARA, S. C. Projetos e Relatórios de Pesquisa em Administração. 16 ed. Campos Elísios SP: Atlas S.A, 2016.

Enviado: Outubro, 2021.

Aprovado: Novembro, 2021. 